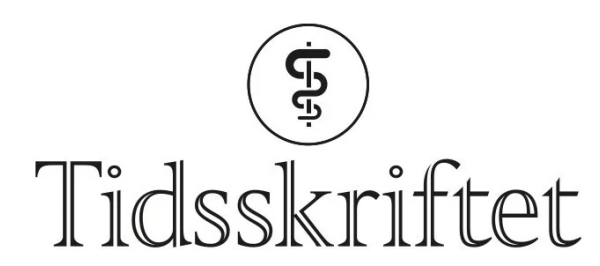

DEN NORSKE LEGEFORENING

\title{
Innsatsstyrt finansiering og dagkirurgi
}

KRONIKK

\section{MARIT LIENG}

Marit Lieng (f. 1965) er spesialist i fødselshjelp og kvinnesykdommer, seksjonssjef ved Gynekologisk avdeling, Oslo universitetssykehus, Ullevål, og førsteamanuensis ved Institutt for klinisk medisin, Universitetet i Oslo. Hun er også engasjert av Norsk pasientskadeerstatning. Forfatter har fylt ut ICMJE-skjemaet og oppgir ingen interessekonflikter. m.lieng@online.no

\section{BJØRN BUSUND}

Bjørn Busund (f. 1954) er spesialist i gynekologi og avdelingsleder ved Gynekologisk avdeling, Oslo universitetssykehus, Ullevål.

Forfatter har fylt ut ICMJE-skjemaet og oppgir følgende interessekonflikter: Han har hatt konsulentoppdrag for Bjørn Busund AS.

\section{JOHAN C. RAEDER}

Johan C. Ræder (f. 1954) er spesialist i anestesiologi, avdelingsoverlege ved Avdeling for anestesiologi, Oslo universitetssykehus, Ullevål, og professor ved Institutt for klinisk medisin, Universitetet i Oslo.

Forfatter har fylt ut ICMJE-skjemaet og oppgir ingen interessekonflikter.

\section{TOR IVERSEN}

Tor Iversen (f. 1952) er samfunnsøkonom, dr.polit. og professor i helseøkonomi ved Avdeling for helseledelse og helseøkonomi, Universitetet i Oslo.

Forfatter har fylt ut ICMJE-skjemaet og oppgir ingen interessekonflikter.

\section{Tall for gynekologisk kirurgi viser at endringer i refusjonslogikk og takster de siste årene ser ut til å slå uheldig ut - både medisinskfaglig og økonomisk. I denne kronikken beskriver vi hvordan endring i finansieringen av dagkirurgi kan påvirke omfanget av dagkirurgisk \\ behandling.}

Dagkirurgisk behandling innebærer at pasienten reiser hjem samme dag etter en operasjon hvor det er behov for anestesipersonell og operasjonsstue/skiftestue. Det er dermed ikke behov for personell hele døgnet. Slik gir dagkirurgi reduserte kostnader for 
helseforetakene. Dagkirurgisk behandling forutsetter bruk av lite invasive operasjonsteknikker og optimalisert anestesi for å begrense postoperativ smerte og kvalme. Men også andre faktorer, som pasientens generelle helsetilstand, prosedyrens kompleksitet samt kompetanse og organisering ved behandlingsstedet vil ha betydning for om en prosedyre kan utføres dagkirurgisk (11). Dagkirurgisk behandling er trygt når retningslinjene følges, og de fleste pasienter foretrekker å reise hjem på operasjonsdagen (2).

Det har vært en overordnet politisk og medisinskfaglig satsing her i landet å øke andelen dagkirurgiske behandlinger. For 20 år siden ble under $25 \%$ av alle inngrep utført dagkirurgisk, i dag gjelder det nærmere $60 \%$ av alle elektive prosedyrer (3). Det er grunn til å tro at det er potensial for fortsatt vekst i andelen dagkirurgi i Norge, både fordi det ved enkelte helseforetak fortsatt gjøres lite dagkirurgi og fordi andelen i våre naboland er høyere.

\section{Innsatsstyrt finansiering}

De regionale helseforetakene har ansvaret for å tilby spesialisthelsetjenester til befolkningen i sin region. Finansieringen av foretakene er i hovedsak todelt - den består av en basisbevilgning og en aktivitetsbasert bevilgning (innsatsstyrt finansering- ISF). ISFrefusjonen beregnes for hvert regionalt helseforetak med utgangspunkt i aktivitet relatert til spesifikke diagnoserelaterte grupper (DRG). Ut fra medisinske og administrative opplysninger om pasienten blir hvert enkelt somatisk sykehusopphold plassert i en DRG. Det finnes om lag 500 DRG-er, og hver har en beregnet kostnadsvekt som justeres årlig.

Kostnadsvektene beregnes med utgangspunkt i pasient- og regnskapsdata fra et utvalg norske sykehus. Dekningsgraden gjennom innsatsstyrt finansering er gjennomsnittstall for store pasient- og diagnosegrupper og vil derfor variere fra pasient til pasient innen samme DRG. Hvert år oppdateres DRG-systemet for å være tilpasset ny medisinsk behandling og/eller praksis og for å korrigere eventuelle feil. Det innhentes årlig kostnadsinformasjon og aktivitetsdata fra sykehusene. Dette danner utgangspunktet for beregning av hva et gjennomsnittsopphold i hver enkelt DRG koster helseforetakene (kostnadsvekt). Disse kostnadsvektene brukes så til å beregne poeng for hver DRG (DRG-poeng), som så gir grunnlaget for ISF-refusjonen gjennom en enhetsrefusjon.

Regjeringen gir, i forslaget til statsbudsjett, størrelsen på enhetsrefusjonen og andelen ISFrefusjon i forhold til full enhetsrefusjon. Denne andelen har variert mellom $40 \%$ og 6o \% siden 2000. Fra 2006 har andelen innsatsstyrt finansering vært 40 \%. For 2013 har Stortinget vedtatt at enhetsrefusjonen skal være 39447 kroner. Med en refusjonssats på $40 \%$ av full enhetsrefusjon gir dette en ISF-refusjon på 15779 kroner per DRG-poeng. Det understrekes fra Helsedirektoratet i regelverket at ISF-refusjonen skal være oppgjør for reell utført aktivitet, men ikke styrende for prioriteringen når det gjelder hvilke pasienter som skal tilbys helsehjelp eller hvilken type helsehjelp de skal få (4).

\section{Finansiering av dagkirurgisk behandling}

Frem til 2009 ble en kirurgisk prosedyre plassert i en DRG uavhengig av om den ble utført dagkirurgisk eller med pasienten innlagt i sykehus. For inngrep hvor beregningsgrunnlaget var noe dagkirurgi og noe innleggelse (ut fra praksis ved referansesykehusene), ble kostnadsvekten en mellomløsning. Det var, som en konsekvens av dette, økonomisk gunstig for helseforetaket med mye dagkirurgi, siden det ikke fullt ut ville få dekket utgiftene knyttet til innleggelse. Systemet hadde en sikkerhetsventil ved at innleggelse som skyldtes komorbiditet eller visse definerte komplikasjoner ga «opprykk» til en DRG med høyere vekt. 
Fra 2009 ble dagkirurgiske prosedyrer plassert i egne diagnoserelaterte grupper. Det ble derfor mulig å differensiere mellom refusjonen for dagkirurgi og døgnkirurgirefusjonen. Bakgrunnen for endringen av refusjonssatsen for dagkirurgisk behandling er at dette er mindre kostbart for helseforetaket enn behandling med innleggelse. De nye kostnadsvektene ble implementert fra 2010.

\section{Gynekologiske operasjoner og endringer i takstsystemet}

De fleste kvinner med en godartet gynekologisk tilstand som krever operativ behandling faller inn under én av tre diagnoserelaterte grupper: DRG 358 (operasjon på uterus/adneks ved godartede sykdommer med komorbiditet eller komplikasjoner), DRG 359 (operasjon på uterus/adneks ved godartede sykdommer uten komorbiditet eller komplikasjoner) og DRG $359 \mathrm{O}$ (dagkirurgisk operasjon på uterus/adneks ved godartede sykdommer). Figur 1a viser kostnadsvektene for DRG 358, DRG 359 og DRG 359O i perioden 2000-13. Det fremgår at refusjonen ved dagkirurgiske inngrep er betydelig redusert etter innføringen av dagkirurgiske DRG-er i 2009.
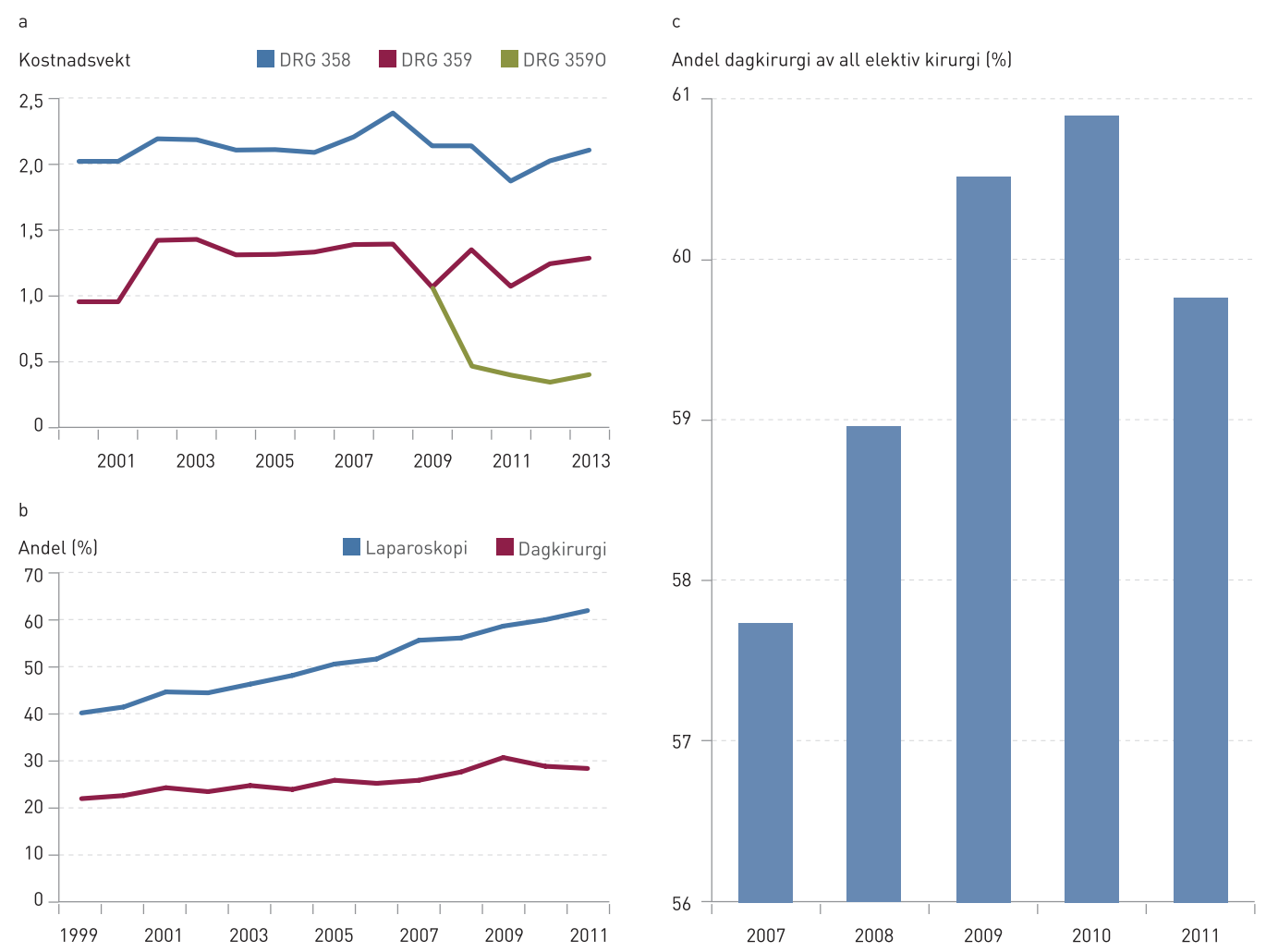

Figur 1 a) Kostnadsvekter for DRG 358 (operasjon på uterus/adneks ved godartede sykdommer med komorbiditet eller komplikasjoner), DRG 359 (operasjon på uterus/adneks ved godartede sykdommer uten komorbiditet eller komplikasjoner) og DRG $359 \mathrm{O}$ (dagkirurgisk operasjon på uterus/adneks ved godartede sykdommer) i perioden 2000-13. DRG 359 O ble innført i 2009. b) Andel laparoskopi og dagkirurgiske inngrep for de fire gynekologiske diagnosene ved alle behandlingsstedene, 1999-11. c) Utvikling i andelen dagkirurgi nasjonalt av all planlagt kirurgi 2007-11, korrigert for endret behandling ved provoserte aborter i perioden og aktivitet ved private klinikker (gir feilkilder i totalmaterialet for dagkirurgisk behandling)

Beregningen av DRG 359 er basert på en gjennomsnittlig innlagt pasient. Her vil de som ligger lenge eller er spesielt ressurskrevende (uten å utløse DRG 358) trekke gjennomsnittet betydelig opp. Kostnaden ved å la en utskrivningsklar pasient være innlagt over natten i en ledig seng er trolig i størrelsesorden 1 0oo-2 ooo kroner, mens det etter 2010 utløser nærmere 15 ooo kroner i ekstra refusjon.

\section{Laparoskopi og dagkirurgi ved gynekologiske avdelinger}


Kikkhullskirurgi (laparoskopi) dominerer i dag ved behandling av en rekke tilstander som tidligere krevde åpen kirurgi. Laparoskopisk kirurgi har åpenbare fordeler sammenliknet med åpen kirurgi. Minimalt invasive operasjonsteknikker som laparoskopi krever kortere sykehusopphold, åpner muligheten for dagkirurgisk behandling og gir kortere rekonvalesensperiode og redusert sykmeldingsbehov (5). Slik bidrar minimalt invasive operasjonsteknikker til bedre behandling for pasientene og til lavere behandlingskostnader både lokalt i helseforetaket og i et samfunnsøkonomisk perspektiv. Kostnadene ved laparoskopi har imidlertid en noe annen fordeling enn tradisjonell kirurgi, da utgiftene til gjenbruks- og engangsutstyr er høyere, mens kostnader knyttet til postoperativ pleie og innleggelse er betydelig lavere.

Det er tidligere vist at bruken av minimalt invasive operasjonsmetoder varierer mye

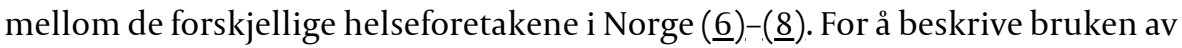
laparoskopi og dagkirurgi ved de enkelte helseforetakene og helseregionene innhentet vi data fra Norsk pasientregister (NPR) fra alle behandlingsforløp for pasienter med en av fire gynekologiske hoveddiagnoser (infertilitet, eggstokkcyste, blødningsforstyrrelser og myoma uteri) ved alle norske gynekologiske avdelinger i perioden 2000-11. Disse diagnosene ble valgt fordi dette er hyppig forekommende tilstander som behandles elektivt ved alle gynekologiske avdelinger og som i stor grad kan behandles med dagkirurgisk laparoskopi. Basert på erfaringer i våre naboland og en klassifikasjon av operative laparoskopiers tekniske vanskelighetsgrad burde det sannsynligvis være mulig og ønskelig å behandle opp mot $80 \%$ av pasientene med disse diagnosene laparoskopisk og anslagsvis $60 \%$ dagkirurgisk $(\underline{1}, 9.9)$.

Datauttrekket fra Norsk pasientregister omfattet totalt 70972 behandlingsopphold. Figur $1 \mathrm{~b}$ viser utviklingen mot en større andel minimalt invasive operasjonsmetoder og en gradvis $\emptyset$ kende andel dagkirurgi for de aktuelle diagnosene i perioden 1999-2011. Etter 2009 flater kurven for dagkirurgi ut og går noe ned. I 2009 ble 31,o \% av de aktuelle prosedyrene utført dagkirurgisk, i 2011 var denne andelen sunket til 28,5\%. Det fremgår av figur $1 \mathrm{~b}$ at stigningen $\mathrm{i}$ andelen dagkirurgisk behandling har stagnert, til tross for at en $\emptyset \mathrm{kt}$ andel dagkirurgi er ønsket fra både et medisinskfaglig og et forvaltningsmessig synspunkt.

\section{Mangel på økonomiske incitamenter}

Dagkirurgisk behandling er trygt og godt for pasientene og økonomisk gunstig, både lokalt i helseforetakene og samfunnsøkonomisk. Vi har vist at økningen i dagkirurgisk behandling for fire vanlige gynekologiske diagnoser har stagnert siden 2009. Nasjonale tall for dagkirurgisk behandling ved alle diagnoser viser et fall i andel på ca. 1 \% fra 2010 til 2011 (fig 1c), til tross for at vi i Norge med en totalandel på rundt 6o \% ligger langt etter Danmark $(80 \%)$ (3). Dette fallet bryter med en jevn, stigende trend på $1 \%$ per år frem til utflatingen i 2010. Da det utføres nærmere 300 ooo elektive inngrep årlig her i landet, kan dette bety at minst 6 ooo pasienter ( $2 \%$ færre dagkirurgiske inngrep i forhold til forventet utvikling) ble unødvendig innlagt i 2011.

Selvfølgelig kan det være mange årsaker til at denne type tall svinger fra år til år, men utover forandringene i takstsystemet er det ingen kjente endringer som skulle tilsi en lavere andel dagkirurgisk behandling etter 2008. Tvert imot burde nye sykehus designet for dagkirurgisk behandling (Akershus universitetssykehus, Sørlandet sykehus, Haukeland universitetssykehus) og økende bruk av bl.a. laparoskopi bidra til fortsatt $\emptyset$ kende andel dagkirurgi. Utviklingen vi beskriver har derfor overveiende sannsynlig sammenheng med endringen i takstsystemet for dagkirurgisk behandling fra 2010.

Før denne endringen utløste en gitt kirurgisk prosedyre samme kostnadsvekt uavhengig av om prosedyren ble utført dagkirurgisk eller med pasienten innlagt i avdelingen. Da dagkirurgisk behandling er kostnadsbesparende, innebar denne løsningen et $\emptyset$ konomisk incitament for dagkirurgi i helseforetakene. De nye kostnadsvektene for dagkirurgi er 
ment å reflektere de reelle kostnadene. Det tidligere økonomiske incitamentet for å gjøre dagkirurgi ble da fjernet. Ved at takstene for innleggelse dels er betydelig høyere, i vårt eksempel fra gynekologien nærmere 15 ooo kroner for én overnatting, blir totalincitamentet negativt.

Vi tror at helsearbeidere alt overveiende setter medisinskfaglige vurderinger i høysetet. Kulturen er preget av pasientenes beste, og det er heller ikke personlig økonomiske interesser knyttet til valg av behandlingsnivå. Imidlertid blir ISF-utbetalinger, i strid med de opprinnelige intensjonene, brukt som styringsverktøy og direkte inntekter til de enkelte avdelinger. Derfor kan det i situasjoner hvor to behandlingsalternativer begge gir optimal pasientsikkerhet, meget vel hende at det skjønnsmessige valg av alternativ blir det som samtidig er mest $\emptyset$ konomisk gunstig for avdelingen. Like uheldig er det at et system med negative økonomiske incentiver vil kunne stoppe en ønsket utvikling. Vi mener det er fagmedisinsk rom for å gjøre flere operasjoner som dagkirurgi i Norge, mens de $\emptyset$ konomiske incentivene tilsier å fortsette med innleggelser.

\section{Hva kan gjøres?}

Finansieringssystemet er et redskap for myndighetene og skal bidra til at målene for helsesektoren oppfylles best mulig. To viktige mål er tilgjengelighet og effektivitet. Effektivitet innebærer at dersom to alternative behandlinger gir like godt resultat, skal den minst ressurskrevende velges. Dagkirurgisk behandling med bruk av minimalt invasive operasjonsteknikker gir like godt eller bedre resultat enn innleggelse for svært mange pasienter. Dette tilsier at DRG-vekten som grunnlag for refusjon burde tilsvare kostnaden ved dagkirurgisk behandling. En slik ordning kan imidlertid skape incentiver som i sin tur fører til at tilgjengeligheten for pasienter som trenger innleggelse, blir dårligere enn den burde være. Hensynet til tilgjengelighet trekker derfor i retning av noe større DRG-vekt for pasienter som trenger innleggelse. Dette er delvis ivaretatt gjennom DRG 358, som tar hensyn til komplikasjoner. Denne gruppen har derfor større vekt enn DRG 359, som er for pasienter uten komplikasjoner. Men ikke alle komplikasjoner fanges opp i DRG $358 \mathrm{i}$ dag. Det trekker i retning av å utvikle systemet slik at alle pasienter som har behov for innleggelse, fanges opp i en DRG for komplikasjoner, mens det for andre pasienter forutsettes utgifter svarende til dagkirurgi.

I Helsedirektoratet aksepterer man ikke betraktningene over og ser bort fra at finansieringssystemet kan påvirke behandlingsbeslutninger. I Samdata 2011 heter det: «For dagkirurgi resulterte endringen i at prisvridningen opphørte og finansielle insentiver ble borte» (3, s. 39). Refusjonen skal ifølge direktoratet samsvare med behandlingskostnadene. Det gjelder også for to alternative behandlingsmåter der det ene alternativet er dominant i den forstand at det både er billigere og gir minst like godt resultat. Et finansieringssystem som tar hensyn til at behandlingsbeslutninger i noen grad kan påvirkes av økonomiske incentiver, vil bidra til et mer robust finansieringssystem enn det vi har nå etter endringene i innsatsstyrt finansiering i 2010.

\section{LITTERATUR}

1. Ræder J, Nordentoft J. Dagkirurgi og anestesi. Tidsskr Nor Legeforen 2010; 130: 742-6. [PubMed]

2. Majholm B, Engbæk J, Bartholdy J et al. Is day surgery safe? A Danish multicentre study of morbidity after 57,709 day surgery procedures. Acta Anaesthesiol Scand 2012; 56:323-31. [PubMed] [CrossRef]

3. Samdata spesialisthelsetjenesten 2011. Oslo: Helsedirektoratet, 2012.

4. Innsatsstyrt finansiering 2011. Oslo: Helsedirektoratet, 2012.

5. Elkington NM, Chou D. A review of total laparoscopic hysterectomy: role, techniques and complications. Curr Opin Obstet Gynecol 20o6; 18:38o-4. [PubMed] [CrossRef] 
6. Oma J. Hvilke faktorer avgjør metodevalget ved hysterektomi på benign indikasjon? Tidsskr Nor Lægeforen 2004; 124: 792-4. [PubMed]

7. Kalseth B, Backe B. Hysterektomi i Norge - fortsatt store praksisvariasjoner og økende omfang. I: Røttingen JA, red. Praksis og kvalitet i sykehus. Trondheim/Oslo: SINTEF/HELTEF, 2002.

8. Goderstad JM, Lieng M, Busund B. Kirurgisk behandling av benigne gynekologiske lidelser. Tidsskr Nor Legeforen 2009; 129: 146o-3. [PubMed]

9. Nordic Federation of Societies of Obstetrics and Gynecology. www.nfog.org (25.3.2013).

Publisert: 7. mai 2013. Tidsskr Nor Legeforen. DOI: 10.4045/tidsskr.13.0155

Mottatt 1.2. 2013, første revisjon innsendt 26.2. 2013, godkjent 25.3. 2013. Medisinsk redaktør Vegard Bruun Wyller.

(C) Tidsskrift for Den norske legeforening 2023. Lastet ned fra tidsskriftet.no 26. april 2023. 